\title{
Margin Trading System and Pricing Efficiency: Evidence from the Chinese Market
}

\author{
Zixin Xu \\ Shenzhen Middle School, Shenzhen 518001, China. \\ xuzixin2001@outlook.com
}

\begin{abstract}
The Margin Trading System is a new creative credit trading system, which was first put into practice in Chinese market in 2010. It is the first time for China to bring in the short selling, which effects have been considered controversially in academics. The paper uses the data of the pilot period, which is 3 months before and after March 31th, 2010 and the fifth expansion period, which is 3 months before and after the December 12th, 2016. Consequently, we get the following conclusions: (1) during the two periods, the Margin Trading System insignificantly increases the price efficiency of the underlying stocks. (2) The stocks with high turnover rate and high price earnings ratio would be affected relatively more by the policy.
\end{abstract}

Keywords: Margin Trading System; Price Efficiency; DID.

\section{Introduction}

In March 30, 2010, the Shanghai Stock Exchange and Shenzhen stock exchange announced that the margin trading system would be open on March 31st and the margin trading members' declarations would begin to be accepted, which means that the margin trading business started. The first targeted stocks are all from Shanghai and Shenzhen stock 50. Until now, the number of the margin trading subjects has been increased for five times (see table1) and the scale of the margin trading system has been increased. The major reasons for choosing these stocks are characteristics of the stock, such as the market value, liquidity and volatility, which are decided by Stock Exchange in China.

Table 1. List Changes

\begin{tabular}{c|c|c|c}
\hline Effective date & No.of additions & No.of removals & No.of Treated Stocks \\
\hline $5 / 12 / 2011$ & 195 & 0 & 285 \\
$31 / 1 / 2013$ & 222 & 7 & 494 \\
$16 / 9 / 2013$ & 206 & 6 & 700 \\
$22 / 9 / 2014$ & 218 & 45 & 873 \\
$12 / 12 / 2016$ & 77 & 0 & 950 \\
\hline
\end{tabular}

During the initial pilot, the securities and investors are restricted to get access into the margin trading. At the same time, investors and brokers have a gradually familiar with the process of new business. December 5, 2011, which is more than a year since the pilot, the number of designated stocks expanded. The scope of the underlying securities extended from 90 to 285 . The second expansion happened on January 31, 2013.It is worth noting that the expansion in January, 2013, not only made SME (small medium-sized enterprise) stocks increased from the original 18 to 66, and it is the first time for the 6 GEM (Growth enterprise market) stocks got involved in the system. On September 2013, the expansion enriched the multi-level structure of the underlying stocks. On September 22, 2014, the margin trading subject is expanded for the fourth times. It is worth noting that this stage is the emergence of explosive margin balance time. On December 12, 2016, the stock of the two subjects is expanded from 873 to 950 . The new underlying subjects are mainly low earnings, relatively large market capitalization, more active trading and relatively stable market performance of the stock. 
The margin-trading system not only enriches the margin trading stock varieties, which meets the diversified investment needs of investors, but also establishes relevant evaluation adjustment mechanism of a two-way adjustment. Eliminating the unqualified securities and transferring to qualified quality securities maintain the stability of stock amount of the underlying securities, and effectively optimize the subject structure, reduce investor risk, improve operational safety of. However, leverage plays an obvious role in enhancing market activity, but as the two sides of a coin, it also accelerated the rate of decline when the market fell. Since the beginning of the June 2015, stock market crashed, so that small investors suffered injuries, and the investors who hold the margin stock are also many strong levels of experience. Since then, although the stock market to recuperate, but the two-financial balance has not rebounded to the peak level but hovering in the trillion below.

The rest of the paper is organized as follows: Section 2 examines the current literature on short sales; Section 3 introduces the methodology and data; Section 4 discusses and analyze the data in two different periods; Section 5 presents conclusions and propounds several suggestions. In particular, we examine which role the short sales play in a bull market.

\section{Literature Review}

The academic discussion of the margin trading arises from the market efficient theory. Fame convinces that an efficient market should be a price market, which could always fully reflect all the available and true information [1]. Miller theorizes that with the presence of the short selling, the probability of downward bias or upward bias will be decreased, for under the short selling, investors could reflect true information [2]. As a result, short selling could lead to a faster price adjustment speed. However, the Margin Trading System's effects on the securities market are still in controversial debate, especially after every financial crisis, margin trades sometimes get restricted by several markets. As a creative credit trading system, the short selling effect in China is still a controversial problem, which is a concern for the government and the academics.

The Margin Trading System is one of the most essential systems in the capitalized market. This system has ready been well-developed in those developed countries' market. Beemer, teal. Point out that during 2000 and 2004, the amount of short sales in the New York stock exchange have already reached $13 \%$ out of all sales [3]. The significant volume, which are brought from the Margin Trading System, especially the short sales, have been proved. However, since the financial crisis in 2008, some countries started to restrict the short sales, for instance, the United States, the United Kingdom and Japan. Consequently, the academics discussed about the Margin Trading System, especially the short selling once again.

On one hand, most of the foreign scholars consider the short selling as one of the most efficient ways of raising the information processing efficiency, speeding up the price discovering, in order push the market to be more efficient. Miller draws the overvaluation conclusion from two assumptions, which are the prohibition of the short sales and the heterogeneous of investors [2]. The paper points out that when different investors hold various opinions toward a particular risk asset, their attitudes would probably be either positive or negative. Without the short selling, however, those investors who hold negative attitudes toward a certain stock could not express their emotion freely. As a result, the security market may possibly reflect a more optimistic valuation than reality, which cause the overvaluation of the stock price. Diamond and Verrocchio theorizes that short sales restraints cause the asymmetric price transmission processes, which could slow down the speed of price adjustment to bad information's [4]. Charles and Owen used the USA short sales data during 1926-1933 to do the research and discovered that the short sales stocks with large short selling costs would have higher valuation and lower yield [6.7]. Using 46 equity markets' data, Bras teal. Tried to investigate the effects, which bring from short sales restrictions to the speed of price discovery. They find strong evidence that short sales could let the price in the market reflect those negative information faster than those markets' price without short sales. They are consistent with Reed's research, which convinced that the short sales restrictions could lead to the asymmetric price adjustment, which is because of the earning announcements [6]. Furthermore, the results are the same with which 
discovered by Safi and Sigurdsson and the Boehner and Wu that short sales have the ability to increase the market price's information efficiency [7.8].

However, Baber and Pagano conducted an empirical study about the effects of the short sales policy enacted by thirty different western countries during the financial crisis from 2008 to 2009 . They suppose that in the down-market, the restrictions of the short sales policy greatly decrease the speed of price discovery. Secondly, some scholars consider that the short sales constraints would increase the collapse risk of the stock market. Hong and Stein present a model, which could show that, with the short sales constraints, the negative information come from the investors could not be expressed timely [9]. Subsequently, the negative information accumulates and break out when the stock market drop. Bras, teal. Use the data from 46 markets, which were the ones with short sales from all over the world [7]. They found that in those market which with short sales constraints, the stock price could not reflect the negative information timely, which would consequently cause the investors' panics, and then, increase the probability of market collapse.

To further illustrate the relationship between the margin trading system, specially the short sales, and the pricing efficiency, the paper using difference-in-difference model to analyze the specific impacts in Chinese markets. The paper mainly contributes to the following aspects. Firstly, this paper offers new evidence in Chinese market to the international controversial problem. Because the large differences between Chinese markets and the developed margin trading markets, the paper which mainly focuses on foreign markets are not available while studying. Secondly, the paper uses the latest data, which could make the results more reliable. Some scholars use the data during the pilot period, which was an immature period. Since 2010 the pilot of margin trading business since the twofinancial business scale has been rapid development, at the end of 2010, the balance of the total margin trading only 10 billion Yuan, and by the end of 2016 and this number has increased to trillion, the peak is reached 2 trillion and 270 billion. Furthermore, the subject of the two melts is also increasing. From the initial 90 increased to the current 950 stocks, its growth is swift. Thirdly, the paper uses the margin trading system as a nature experiment to avoid endogeneity. In this way, it could better control the factors that could affect the final conclusions and make the results more accurate.

\section{Methodology}

\subsection{Data}

In the paper, we use the data from the pilot period and the period after the fifth expansion in order to make contrast. We want to figure out whether the effects bring from the margin trading system have changed.

The paper takes March 31st, 2010 as the midpoint of the pilot period, and both chooses three months before and after the midpoint, which is 135 dealing days from December 18th, 2009 to July 9th, 2010. During this period, the security market was down market, the Shanghai Composite Index fell from 3154.82 to 2319.74 , and then calculate the monthly average yield is $-4.6 \%$. Firstly, the paper chooses 50 stocks, which were the first underlying stocks as the treatment group and choose the rest in the Shanghai Stock Exchange 180 Index Components as the controlled group. Then exclude the stocks, which index changes or margin target changes occurred, and the ones which became listed a month before March31st, 2010. For the treatment group, exclude the stocks which trading days are less than 125 days. For the controlled group, take out the stocks which trading days less than 130 days. In this way, we could reduce the impact of special events such as stop, resume trading and new listing. Consequently, a total of 41 treatment group and 42 control group were obtained.

On December 12nd, the subject stocks in the Chinese market was expanded for the fifth time. The paper chooses the time period from September 12nd, 2016 to December 9th, 2016 as the window before the fifth expansion, and from December 12nd, 2016 to March 17th, 2017 as the window after the expansion. The data of the Price earnings ratio, the turnover rate, the market capitalization and the circulation market value are all picked up from the Wind. Firstly, although there are 40 stocks which become to be the underlying stocks after the fifth expansion, we only pick out 39 stocks as the 
treatment group because one stock is suspended several months during the period. Secondly, we choose 43 stocks as the controlled group. All of the 43 stocks are select by the formula of the weighted evaluation index from Shanghai Stock Exchange first. Then we consider the pricing earnings ratio and listing date: we take away the ones with the over $500 \mathrm{P} / \mathrm{E}$ ratio or the negative P/E ratio; we take away the stocks which became listed after 2016 as well. Finally, we get 40 for the treatment group and 43 for the control group.

For the independent variable, we use $\mathrm{R}$ to evaluate the price efficiency. Roll was the first scholar who used the $\mathrm{R}^{2}$ in the stocks corresponding regression equation of the market revenue as the index of measuring the relevance between the individual stock and the stock market. The smaller $\mathrm{R}$ is, the weeklies that the risk of public information and the system of the market for the stock price movements express, which means, the larger capacity of the private information the individual stock has, the higher pricing efficiency the individual stock has.

\subsection{Model}

Difference-in Difference (DID) model is an efficient way to evaluate the policy's effect. Ashenfelter and Card used the DID model in their research the earliest [11]. They used the DID to study the "Comprehensive Employment and Training Act" project, which was held in 1976. Since then, the DID model was widely used in academic discussion.

In the paper, the practice of Margin Trading System could be considered as a nature experiment. We use the DID model to evaluate the effect of Margin Trading System during the pilot period and fifth expansion period in China. The model setting is as following:

$$
y_{i, t}=\beta_{0}+\beta_{1} \text { time }+\beta_{2} \text { Group } \beta_{3} \text { time } \text { Group }+\Sigma \text { Control }_{i, t}+\mu_{i, t}
$$

The Group is the dummy variable of different group (Group 1, which is the listed stocks, and group 0 , which is the non-underlying stocks), time represents the different two time periods (Time period 0 , which is before the short sales policy was put into effect, and the period 2, which is after the short sales was put into effect). Control represents some control variables such as the PE ratio, value and turnover rate. (We take the logarithmic of the value in the data table) The concerning coefficient is the coefficient of the intersection, which evaluate the policy effect. The higher coefficient means the less private information, which would consequently mean the lower pricing efficiency.

\section{Results}

\subsection{Statistic Description}

In the paper, period 1 refers to the pilot period, which is from December 18th, 2009 to July 9th, 2010, period 2 refers to the period after the fifth expansion, which is from December 12nd, 2016 to March 17th, 2017. We consider the price earnings ratio, the turnover rate and the value of the stocks as the control variables, while the efficient is the dependent variable. $t=0$ refers to the chosen time period before the fifth expansion, while $\mathrm{t}=1$ refers to the chosen time period after the fifth expansion. We consider the price efficiency as the indicator of whether the policy is effective. The rising price efficiency could indicate the effectiveness of the policy. The concrete outcome of the effectiveness reflects on the reduction of $r$ square, since the reduction of $r$ square implies that the prices of stocks reflect more private information, instead of fluctuating with the overall market direction.

Table 2. The Statistic Table of Variable "PE"

\begin{tabular}{r|ccccc}
\hline & Control period 1 & Treated period 1 & Control period 2 & Treated period 2 \\
\hline $\mathrm{t}=0$ & 60.861 & 26.889 & 42.159 & 25.336 \\
\hline $\mathrm{t}=1$ & 47.125 & 22.320 & 37.964 & 29.9952 \\
\hline
\end{tabular}


According to table 2, it is obvious that the price earnings ratio of the two groups changed a lot in period 1 when $t=0$. When $t=1$, the price earnings ratio reduces significantly. During period 2 , the price earnings ratio reduces a lot when $\mathrm{t}=0$, while when $\mathrm{t}=1$, the price earnings ratio reduces.

Table 3. The Statistic Table of Variable "Turnover"

\begin{tabular}{r|cccc}
\hline & Control period 1 & Treated period 1 & Control period 2 & Treated period 2 \\
\hline $\mathrm{t}=0$ & 1.707 & 1.026 & 2.708 & 1.302 \\
\hline $\mathrm{t}=1$ & 1.375 & 0.908 & 1.583 & 1.463 \\
\hline
\end{tabular}

According to table 3 , the value of the stocks reduces significantly. In period 1, the turnover rate of the stocks reduces. During period 2, the turnover rate reduces a little. When $t=1$, the turnover rate reduce.

Table 4. The Statistic Table of Variable "Value"

\begin{tabular}{c|cccc}
\hline & $\begin{array}{c}\text { Control } \\
\text { period 1 }\end{array}$ & $\begin{array}{c}\text { Treated } \\
\text { period 1 }\end{array}$ & $\begin{array}{c}\text { Control } \\
\text { period 2 }\end{array}$ & $\begin{array}{c}\text { Treated } \\
\text { period 2 }\end{array}$ \\
\hline $\mathrm{t}=0$ & 5.889 & 6.575 & 5.843 & 6.074 \\
\hline $\mathrm{t}=1$ & 5.818 & 6.464 & 5.819 & 6.090 \\
\hline
\end{tabular}

The value of the stocks reduces significantly. When $\mathrm{t}=1$, the value of the stocks increases a little. During period 2, the value of the stocks has an insignificant increment. When $t=1$, the value of the stocks increases insignificantly.

Table 5. The Statistic Table of Variable "Efficient"

\begin{tabular}{r|ccccc}
\hline & $\begin{array}{c}\text { Control group } \\
\text { period 1 }\end{array}$ & $\begin{array}{c}\text { Treated group } \\
\text { period 1 }\end{array}$ & \multicolumn{1}{c}{$\begin{array}{c}\text { Control group } \\
\text { period 2 }\end{array}$} & $\begin{array}{c}\text { Treated group } \\
\text { period 2 }\end{array}$ \\
\hline $\mathrm{t}=0$ & 0.225 & 0.334 & 0.215 & 0.293 \\
\hline $\mathrm{t}=1$ & 0.367 & 0.426 & 0.242 & 0.270 \\
\hline
\end{tabular}

For the price efficiency during the pilot period, the efficiency of the treated group is higher than the control groups in $\mathrm{t}=0$ or $\mathrm{t}=1$, which indicates that the treated group is more synchronous with the market than the control group, no matter before or after the short sales is put into effect. During the pilot period, after the new policy was put into practice, the $r$ square of the treated group was higher than it was before, which implies that the policy did not lead to a higher price efficiency. However, during the period of the fifth expansion of the underlying stocks, the $r$ square of the treated group got lower after the policy was put into effect, which indicates that the new policy has positive effects on the price efficiency. After six years, the mean of efficient of the underlying stocks has decreased a lot, which means $r$ square decreased, implying that the price efficiency has been improved.

\subsection{Regression Results}

Table 6 shows the OLS regression results of underlying stocks in the pilot period. In the pilot period, we pay attention to the core coefficient of intersection item, which is -0.0495 in model 1 , and -0.0427 in model 2 . It affects the pricing efficiency negatively but not significant. We add 3 more control variables in model 2 , which are the turnover, price earnings ratio and the value of the stocks. We could find that the coefficient of the intersection item reduces but does not change much. These 2 models both present negative insignificant effects to the pricing efficiency, which indicate that the short sales policy does not affect the pricing efficiency much, but the insignificant reduction still 
prove that the public information include in the pricing efficiency have reduced, and the private information have increased. The pricing efficiency increased consequently.

Then, we focus on these three control variables in the Model 2. As we can see from table 6, the turnover affects the pricing efficiency negatively and significantly at the level of 5\%. This indicates that stocks with higher turnover rate would be affected more by the policy. The price earnings ratio, which is one the commonest used factors for determining the reasonability of the stocks' prices, and the value of stocks, which is the market price of the stocks, could also negatively affect the pricing efficiency insignificantly.

Table 6. The regression results of the pilot period with STATA

\begin{tabular}{c|c|c}
\hline & Model 1 & Model 2 \\
& Efficient & $0.129^{* * *}$ \\
\multirow{2}{*}{ Time } & $0.141^{* * *}$ & $(4,47)$ \\
\hline \multirow{2}{*}{ Group } & $(4.82)$ & $0.0955^{*}$ \\
& $0.109^{* * *}$ & $(2.20)$ \\
\hline \multirow{2}{*}{ Timegroup } & $(3.52)$ & -0.0427 \\
& -0.0495 & $(-0.97)$ \\
\hline \multirow{2}{*}{ Turnover } & $(-1.11)$ & $-0.0298^{*}$ \\
& & $(-0.257)$ \\
\hline \multirow{2}{*}{ Pe } & & -0.000106 \\
& & $(-0.92)$ \\
\hline \multirow{2}{*}{ Value } & & -0.00673 \\
& & $(-0.43)$ \\
\hline \multirow{2}{*}{ Cons } & $(10.12)$ & 0.436 \\
N & 166 & $(1.20)$ \\
\hline
\end{tabular}

$* \mathrm{p}<0.05, * * \mathrm{p}<0.01, * * * \mathrm{p}<0.001$

For the period of the fifth expansion (Table 7), we concentrated on the coefficient of the interaction item, which is -0.0510 in model 1 , and -0.0314 in model 2 . It affects the price efficiency negatively but not significant. We add three more control variables in model 2, which is the turnover, the price earnings ratio and the value of the stocks. Obviously, the coefficient of the intersection item reduces but does not change much, and these two models both show the negative insignificant effects to the market, which indicates that the margin trading policy does not affect the pricing efficiency much. However, the existence of the insignificant reduction still presents that the reduction of the public information, which means the increment of the private information. As a result, the price efficiency also gets higher.

Furthermore, compare to the model 2 in the pilot period, the coefficient of the intersection item has decreased from -0.0427 to $4-0.0314$, which means the private information has increased and the price efficiency gets higher as well, which could prove that the from the margin trading system was put into practice in 2010, to its fifth expansion in 2016, the margin trading system has been developed more in Chinese market and has played a more critical role in the security market. The price earnings ratio affects the price efficiency negatively and significantly at a level of $1 \%$. The turnover rate affects the price efficiency negatively while the value of the stock affects positively. 
Table 7. The regression results of the fifth expansion with STATA

\begin{tabular}{c|c|c}
\hline \multirow{2}{*}{ Time } & (1) Efficient & (2) Efficient \\
Group & $0.0274(0.93)$ & $0.0158(0.49)$ \\
\hline Timegroup & $0.0785^{*}(2.17)$ & $0.0428(1.07)$ \\
\hline Turnover & $-0.0510(-1.02)$ & $-0.0314(-0.61)$ \\
\hline Pe & & $-0.00462(-0.36)$ \\
\hline Value & & $-0.00160^{* *}(-3.25)$ \\
Cons & $0.215^{* * *}(10.07)$ & 0.00445 \\
$\mathrm{~N}$ & 164 & $0.235(0.77)$ \\
\hline$* \mathrm{p}<0.05, * * \mathrm{p}<0.01, * * * \mathrm{p}<0.001$ & & 164 \\
\hline
\end{tabular}

\subsection{Comparison}

These two period both present the negative and insignificant effects of the margin trading system toward the market. When we add three more control variables in the model 2 of both period, the coefficient of the intersection item would reduce, which implies that the privation information included in has increased, and the price efficiency becomes higher. In the pilot period, the margin trading system was first put into practice in Chinese market, so it did not develop that well and did not affect the market much yet. The fifth expansion took place in 2016, which is six years already since the beginning of the margin trading system in Chinese market. During these years, the margin trading system has developed much more, more and more stocks has been being underlying. As a result, the coefficient of the intersection item in model 2 of the period after the fifth expansion has reduced, comparing to the coefficient in model 2 of pilot period.

The market in the pilot period is a bear market, which means the market is a down market. The market after the fifth expansion is a bull market, accompanying with a shock rise. The impact of the margin trading system in these two completely opposite markets were completely different.

In the background of bear market, margin trading does not improve the pricing efficiency, though financing transactions will increase the quality of the reflection of private information in stocks in a certain extent. But in the bear market, investors tend to be panic, resulting in herd effect, and sell stocks through financial securities transactions irrationally, so as to strengthen the co-movement between stock and market. These two opposing forces will make the impact of margin trading system weak. Therefore, the financing system could not immediately improve the pricing efficiency for the Chinese securities market in the pilot period or in the down market.

Furthermore, during the rising period, the financing transaction will enlarge the capital and boost the price increment, and consequently reducing the price efficiency. At the same time, the margin trading development become more mature, so the margin trading system could reflect more negative private information, but the result is still not significant. This can be explained by the small scale of Chinese margin trading market. Financing transactions through funds provide investors with sufficient funds to enlarge the chase, thereby increasing the stock and market association. Even if the margin trading can bring more private information, but because of the scale, even if the policy is effective at this stage, it will be even subtler and less effective than in the falling period.

\section{Conclusion}

The paper mainly discusses the effects of the Margin Trading system on the Chinese market, and focus on analyzing the different effects, which are brought from this new credit trading policy, among different periods of the Chinese market. Because of the existence of the endogeneity, it is hard to 
recognize the effects of the policy on the price of the stocks, for several factors affect the price simultaneously. As a result, on the background of the nature experiment, we use the DID model to do the research.

We refer the policy enforcement as a natural experiment, using the DID model to research the effects of the short sales on the price of stocks. In the paper, we use the data during the pilot period of the short sales in Chinese market and the period of the fifth expansion of the underlying stocks, restrict the effect which may brought by the endogeneity and consequently get reliable evidence for the effects of the short sales restriction on the price of the stocks. With the analysis of the data above, we get the following conclusions: Firstly, during the two periods, the Margin Trading System insignificantly increases the price efficiency of the underlying stocks. Secondly, the stocks with high turnover rate and high price earnings ratios would be affected relatively more by the policy, which means the higher turnover rate and the price earnings ratio, the more sensitive stock.

Based on the research, we raise the following suggestions: Firstly, enlarge the range of the underlying stocks, for from the beginning of the short sales policy was put into effect in the Chinese market, the investors could only borrow capital or stocks from the limited securities trader and it was far from the need; Secondly, use the experience of other countries for reference, consider to take various standards of short sales among different categories of stock. For instance, in order to reduce the possibilities of overpricing, it is available to take a slacker restriction of short sales; In order to control the extraordinary volatility of those stocks with high volatility, it is probable to loosen restrictions of the cost of short sales for the particular kind of stocks.

\section{References}

[1]. Fame, Eugene F., 1970, efficient capital markets: A review of theory and empirical work [J]. Journal of Finance 25(2), (1970), 383-417.

[2]. Miller. E., 1977, Risk, Uncertainty, and divergence of opinion [J]. Journal of Finance 32 (4), 1151-1168.

[3]. Boehner, E, Charles M. Jones, and Liaoyang Zhang, 2008, which shorts are informed? [J]. The journal of Finance, 63 (2), 491-527

[4]. Diamond, Douglas W., and Robert E. Verrocchio, 1987, Constraints on short selling and asset price adjustment to private information [J]. Journal of Finance Economics 18 (2), 277-311.

[5]. Charles M. J. and Owen A. L., 2002, Short Sale Constraints and Stock Returns [J]. Journal of Financial Economics, 66 (2), 207- 239.

[6]. Bras, Arturo. William N. Goetz Mann, and Ming Zhu.2007 Efficiency and the bear: Short sales and market around the world [J]. The journal of Finance, 62(3), 1029-1079.

[7]. Safi P. A. C. and Sigurdsson K., 2011, Price Efficiency and Short Selling [J]. The Review of Financial Studies, 24(3), 821-852.

[8]. Boehme and Julie $\mathrm{Wu}, 2012$, short selling and the price discovery process [J]. Review of Financial Studies (forthcoming), 26(2), 287- 322.

[9]. Hong, Harrison, and Jeremy C. Stein, 2003, Differences of opinion, short -sales constraints, and market crashes [J]. Review of Financial Studies 16 (2), 487- 525.

[10]. Hour, Key, and Tobias J. Markowitz., 2005, Market frictions, price delay, and the crosssection of expected returns [J]. Review of Financial Studies, 18(3), 981-1020.

[11]. Ashen filter O. and Card D., 1985, using the Longitudinal Structure of Earnings to Estimate the Effect of Training Programs [J]. Review of Economics and Statistics, 67(4), 648- 660. 